\title{
Paròdia sobre paròdia. C. A. Jordana reescrit per Mercè Rodoreda
}

\author{
Parody over parody. \\ C. A. Jordana rewritten by Mercè Rodoreda
}

\author{
Catalina Mir \\ Universitat de Barcelona \\ catalina.mir@ub.edu
}

\begin{abstract}
This paper proposes a reinterpretation of plot parallelisms between El collar de la Núria (1927), by C. A. Jordana, and Crim (1936), by Mercè Rodoreda. The comparative analysis aims to show how Crim, in addition to working as a parody of the principles of the detective story, can be read as a parody of an earlier parody of the same genre - that is, the text by Jordana. This rewriting exercise strengthens the hypertextual link between these two novels and results in what we may call, following the terminology by Gérard Genette, a hyperparody.
\end{abstract}

Keywords: detective story, parody, hypertextuality, C. A. Jordana, Mercè Rodoreda

L'any 1961 Albert Manent publica a Serra d'Or una enquesta a Rafael Tasis i Manuel de Pedrolo sobre la novel·la policíaca a Catalunya. D'aquest document, ha estat citada profusament una de les respostes de l'autor de l'Aranyó, en què expressa l'aposta pel gènere de lladres i serenos per fer guanyar, a la literatura catalana, un bon nombre de lectors "poc familiaritzats amb el català escrit i massa mandrosos per a lliurar-se a l'esforç que, a llur entendre, suposa el fet d'abordar un llibre de més tonatge literari" (Manent, 1961, p. 14). En aquest cas m'interessa de destacar una altra part de l'entrevista, no tan recordada: la resposta que un i altre autor donen a la 
pregunta de si la novel·la policíaca té tradició o un passat "gaire brillant" (Manent, 1961, p. 13), en l'àmbit català. Tots dos responen negativament i esmenten l'únic text, dels que han llegit, que consideren que s'ajusta a les normes del gènere: Rafael Tasis cita El collar de la Núria (1927) de C. A. Jordana ${ }^{1}$; i Pedrolo, Crim (1936) de Mercè Rodoreda. Curiosament, dues paròdies.

La connexió entre les dues narracions no es funda pas, però, en aquesta doble entrevista de Manent, ni en la compartida condició paròdica. La jove autora és qui l'estableix motu proprio a partir de les nombroses al·lusions que inclou, a Crim, a l'obra i la figura de Jordana, ja en el pròleg ${ }^{2}$. Aquesta intertextualitat ha estat comentada en diversos estudis sobre l'escriptora, des de Carme Arnau (1979) fins a Carme Gregori (2016), passant per Cortés (2001) i per l'edició de les novel·les de preguerra a cura de Roser Porta entre 2002 i 2006. Pel que fa a la faceta narratològica, els diferents treballs han presentat el vincle intertextual a partir de la reutilització del recurs del collar desaparegut; i Cortés, en la seva investigació, també ha assenyalat algunes equivalències entre els personatges d'un relat $i$ altre.

Amb tot, en aquest ordre de coses hi ha un aspecte no tan tractat, l'argument, que pot revelar un nexe més profund entre els dos textos. Per indagar-hi, aquest article planteja que Crim és un hipertext d'El collar de la Núria -en el sentit que estableix Gérard Genette (1982)- en la lectura del qual pot reconèixer-s'hi la història del llibre de C. A. Jordana "reescrita" per Rodoreda. Es proposa, així, una reinterpretació dels paral·lelismes argumentals existents mitjançant una anàlisi comparativa basada en la narratologia i en les representacions simbòliques del collar. Tot plegat, amb l'objectiu de complementar els estudis que han encetat aquesta línia d'investigació i, més generalment, de donar a conèixer els orígens i les característiques de la narrativa criminal en llengua catalana.

${ }^{1}$ Tasis va encara més enllà i planteja la idea de crear un premi de novel·la policíaca en català que faci honor a l'autor d'El món de Joan Ferrer: "[...] em sembla que caldria donar-li, en homenatge a un escriptor que, en circumstàncies normals, segurament hauria produït bones novel les policíaques, el nom de C. A. Jordana" (Manent, 1961, p. 13).

${ }^{2}$ El pròleg inclou un resum biobibliogràfic, en què l'autora escriu: "Va seguir a aquest primer [1libre], el segon: Del que hom no pot fugir (Edicions Clarisme), títol gramaticalment incorrecte segons el prestigiós gramàtic i escriptor C. A. Jordana" (Rodoreda, 2006, p. 296-297). Aquest és un apunt humorístic sense fonament real, atès que, com indica la curadora del volum, Roser Porta, no s'ha trobat cap ressenya de l'autor que parli d'aquest títol de Rodoreda. Vegeu també les notes núm. 16, 24 i 30 (p. 126, 130 i 136), que posen en clar algunes referències a $\mathrm{C}$. A. Jordana. 


\section{ANTECEDENTS}

Les dues obres s'insereixen en la tradició del gènere de la novel·la d'enigma anglesa des de la paròdia ${ }^{3}$. Ja en el pròleg de Crim, la història es presenta en aquests termes: "paròdia de novel·la policíaca" (Rodoreda, 2006, p. 297)4. Recordem que aquesta forma literària és essencialment un exercici de reescriptura amb intencionalitat còmica. "It provides a new version of an old story", glossa Michelle Hannoosh (1989, p. 114), que també en destaca el caràcter autoreflexiu. El referent versionat, recull Gregori (2016, p. 478) d'acord amb Linda Hutcheon (1985), pot ser tant una obra concreta com -en una concepció més àmplia de la paròdia- un gènere literari, una estètica o un moviment.

Fet $\mathrm{i}$ fet, en les primeres dècades del segle $\mathrm{xx}$-quan s'introdueix el gènere a l'Estat espanyol-, la majoria de novel-listes que s'aventuren a practicar-lo ho fan a través del tractament humorístic i fins i tot la ridiculització dels principis que regeixen la narració policíaca (Vázquez de Parga, 1993, p. 37). A mitjans dels anys vint, comencen a proliferar les col·leccions populars de novel·la que acullen tant obres signades per escriptors autòctons com traduccions. Als Quaderns Literaris de Josep Janés, per exemple, que és on es publica Crim, es donen a conèixer també alguns títols d'Edgar Allan Poe traduits per Carles Riba, com Els assassinats del carrer Morgue (1934, núm. 27) i La caiguda de la casa Usher (1935, núm. 80). I, així mateix, C. A. Jordana hi feia feines de traducció.

Tant ell com Mercè Rodoreda són, doncs, escriptors procedents d'altres àmbits que, seguint aquesta tendència, incideixen en el gènere "bien con fines experimentales o paródicos, bien utilizándolo más o menos conscientemente como medio para alcanzar objetivos particulares" (Vázquez de Parga, 1993, p. 13). Efectivament, si bé l'autora de Crim va parlar obertament de la seva afició a la literatura criminal en diverses entrevistes (p. ex., Roig, 1976, p. 168)5, a la llarga l'episodi de creació d'un relat d'aquesta mena ha quedat diluït en una anècdota de joventut eminentment atribuïble a la voluntat d'experimentació, del resultat de la qual es desentén completament (de la mateixa manera que rebutja la resta de producció de preguerra, a excepció d'Aloma).

${ }^{3}$ En aquest model, es produeix la comissió d'un crim en un ambient de classes altes -generalment en un espai tancat-i té lloc la intervenció d'un detectiu privat amb elevades capacitats intel·lectuals que, finalment, dona una solució racional al misteri que semblava irresoluble.

${ }^{4}$ Cito de l'edició a cura de Roser Porta (Rodoreda, 2006, p. 115-298), de la qual em limitaré a assenyalar el número de pàgina sense altres indicacions.

${ }^{5}$ Alguns títols de l'època que segurament influenciaren Rodoreda són L'assassí i el seu compliç (1924) de Jacint M. Mustieles; La meva mort (1924) de Miquel Poal-Aregal; El misteri del bosc d'Aubac (1926) de Jaume Roig Solanas, i Com vaig assassinar Georgina (1930) de Domènec Guansé. 
En canvi, per a Jordana, l'escriptura d'El collar de la Núria devia respondre a un exercici literari més premeditat, relacionable amb la voluntat de contribuir al projecte de modernització cultural. Maria Campillo ha assenyalat que:

C. A. Jordana era conscient de formar part d'una petita legió de "treballadors de la cultura" que, en els anys trenta, s'esforçaven per creure en la definitiva normalitat de les lletres catalanes i contribuïen activament a entronitzar-la, no només des de posicions més o menys privilegiades com a escriptors per a un públic selecte, sinó també, i sobretot, cobrint camps intermedis, més majoritaris. En la recerca d'un públic ampli per al català i, per tant, en la necessitat de servir-li uns productes adequats, trobem el sentit de moltes coses, des de la traducció digna de clàssics i moderns estrangers fins als manualets de divulgació gramatical per a la Barcino, passant, naturalment, per la producció de gèneres comercials o comercialitzables. $(1993$, p. 5)

Com la novel·la de gènere "comercialitzable" que és, El collar de la Núria va aparèixer en una editorial de consum, Mentora, però va assolir una "difusió mínima" (Porta, 2007, p. 243) i no va ser reeditada fins l'any 1988 a la Biblioteca Popular de Curial. Tantes dècades d'inaccessibilitat no passaren per alt a la crítica: a tall d'exemple, en un article publicat en premsa el 19 de novembre de 1975, titulat "Confinaments literaris", Robert Saladrigas esmentava Cèsar August Jordana entre els novellistes catalans "introbables" (1979, p. 67), i reivindicava la necessitat d'una "política sistemàtica de reedicions" (p. 71). La condició d'introbable, malgrat tot, encara avui pot aplicar-se al text que aquí analitzo, que, oblidat pel públic lector, és pres en consideració gairebé sols en qualitat de referent del de Rodoreda.

No hi ha dubte que l'autora de La plaça del Diamant havia llegit la paròdia policíaca de 1927 i n'admirava l'autor. Si fem un breu repàs de la relació entre les dues figures, destaca el fet que l'any 1933, amb vint-i-cinc anys, l'escriptora havia entrevistat C. A. Jordana per a Clarisme (Muñoz, 1992, p. 495-573). I el 1939, tots dos a l'exili després de fugir de Barcelona en el conegut bibliobús i de l'estada al castell de Roissy-en-Brie, mantingueren una breu relació epistolar (Campillo, 2006). A tot això, tornant a l'esfera estrictament literària, s'hi pot afegir que l'exercici intertextual de Rodoreda és present en una altra novel-la dels anys trenta, Aloma-1libre que escriu paral·lelament a Crim i amb el qual obté el Premi Crexells de l'any 1937-, en què la protagonista llegeix Una mena d'amor, narració eròtica de Jordana publicada el 1931 a Edicions Proa ${ }^{6}$. Tanmateix, mentre que en aquest cas la referència no depassa la simple menció, Crim sí que presenta múltiples correlacions argumentals amb $\mathrm{El} \mathrm{Co}$ llar de la Núria, fins al punt, com s'ha assenyalat, de poder-se considerar un hipertext d'aquesta obra. Gérard Genette defineix la hipertextualitat com "toute relation unis-

${ }^{6}$ El títol és una mostra més que C. A. Jordana, pel fet de ser un escriptor culte, no deixà de cultivar diferents modalitats de la literatura de gènere: la policíaca, l'eròtica i així mateix la fantàstica: Víctor Martínez-Gil (2004) inclou un conte seu, "La pastilla de sabó", dins la seva famosa antologia de narrativa no mimètica, on també figura una narració de Mercè Rodoreda, "La salamandra". 
sant un texte B (que j'appellerai hypertexte) à un texte antérieur A (que j'appellerai, bien sûr, hypotexte)" (1982, p. 11). L'hipertext evoca l'hipotext:

[...] plus o moins manifestement, sans nécessairement parler de lui et le citer. L'Énéide et Ulysse sont sans doute, à des degrés et certainement à des titres divers, deux (parmi d'autres) hypertextes d'un même hypotexte: l'Odyssée, bien sûr. Comme on le voit par ses exemples, l'hypertext est plus couramment que le métatexte considéré comme une œuvre "proprement littéraire". (p. 12)

A més a més, aquesta relació es pot establir per dues vies: o bé narrant una història nova imitant la forma d'una d'anterior -com fa Virgili a l'Eneida, emmirallant-se en l'estil èpic d'Homer-, o bé reescrivint un relat ja existent d'una manera completament diferent, com fa James Joyce amb el periple d'Ulisses. Atenent la trama i, sobretot, el desenllaç (no pas la tècnica narrativa), Crim respon a la segona casuística plantejada.

Finalment, en vista de l'anàlisi argumental d'una obra i l'altra, cal ressaltar l'element del collar i la seva tradicional associació simbòlica al lligam social. El collar representa un vincle entre qui el porta i qui l'ha entregat o imposat (Chevalier \& Gheerbrant, 1986, p. 330); en un sentit més còsmic, com a suma de múltiples peces entrellaçades que és, simbolitza la unió sobre la desintegració, l'ordre sobre la diversitat caòtica. En envoltar el coll d'una persona, la insereix figurativament en un determinat cercle social i alhora exhibeix un estatus -concretament, en el parell de casos aquí tractats, el de la burgesia benestant-. S'entén, per tant, que la desaparició d'aquesta joia equivaldrà a la transgressió de tal ordre social i moral: aquesta és, de fet, la funció tradicional del crim, en el gènere, si bé el que sol desmantellar l'estat natural de les coses és un assassinat, absent en aquestes dues novel·les per la seva condició de paròdia.

Ara bé, s'escau que en els dos textos la pèrdua del collar és propiciada per la mateixa portadora -la Núria i la Rut, respectivament- amb l'objectiu de desviar-se del camí vital marcat per la col·lectivitat. Anant de dret a la resolució d'aquest conflicte constatem que, en la narració de Jordana, el capgirament desitjat per la Núria té èxit, de manera contrària al que ocorre en la de Rodoreda, en què la Rut finalment recula en les seves intencions. Per examinar el desenllaç amb totes les seves implicacions, caldria doncs revisar l'argument de les dues obres a la llum d'algunes citacions representatives.

\section{ANÀLISI ARGUMENTAL DE LES NOVEL·LES}

\subsection{EL CRIT DE LA DAMA I LA DESAPARICIÓ DEL COLLAR}

El collar de la Núria és un enfilall de perles de cinquanta mil duros que el padrastre, Mr. Esteve Xuriguer, un important financer català, li regala amb motiu de la seva tornada a Barcelona després d'un temps de Londres -on, com se sabrà més endavant, la noia s'ha relacionat amb el món aristocràtic i ha tingut temps d'avorrir-se "per 
sempre" (p. 131)-7 . L'obsequi és comprat i entregat al març, i a l'agost del mateix any és quan, presumptament, té lloc l'intent de robatori. Els fets ocorren a Vil·la Dick, la casa d'estiueig de la família Xuriguer, a Arenys de Mar, durant una nit calorosa.

A més dels amfitrions i del personal de servei, a la vil·la s'allotgen tres convidats: Cèsar Franc -el narrador de la història, secretament enamorat de la Núria-, Parnell Samvitx -cosí de la Núria i col·lega de Cèsar Franc-i Ramon de Ramonet -un jove de família aristocràtica, pretendent de la noia i protegit de Mr. Xuriguer-. Aquesta triple presència masculina és la que motiva que la Núria hagi d'intercanviar, a desgana, l'habitació amb el seu padrastre, per no passar la nit en un pis amb tres homes. Poca estona després que s'hagi retirat a la nova cambra, però, la noia emet un crit d'auxili esgarrifós. Tots corren a veure què passa i escolten el seu relat: "Dormia... -anà dient ella, a poc a poc, amb veu tremolosa-, dormia malament... M'he despertat de sobte... i he vist una cara... amb una barbassa... i uns ulls furiosos... Després... he sentit que m'estrenyien el coll... unes mans... He pogut deseixir-me'n un moment... i he cridat... No sé... res... més..." (p. 31).

Evidentment la Núria, al coll, hi porta les perles. Tanmateix, no és fins que arriba a la casa un detectiu "britànic", Mr. Fog, que es confirma que el mòbil de l'atac ha estat el furt del collar i que, contràriament al que semblava, el lladre ha portat a terme la seva acció. Quan l'investigador examina la joia amb la "famosa lupa" (p. 75), sentencia: "Sempre he cregut que el vostre agressor, l'anomenat «barbut», volia apoderar-se del vostre collar, Miss Núria. Us heu despertat dues vegades amb les mans del barbut al coll. Doncs bé! El lladre ha aconseguit el seu propòsit. Les perles d'aquest collar són falses" (p. 87). La teoria de substitució de collars és la que guiarà les perquisicions de Mr. Fog a partir d'aquest punt.

L'enigma de Crim també s'enceta en horari nocturn, en el marc d'una vetllada al xalet del novel-lista Marià Frena, a Barcelona (aquí, però, es respecta la unitat d'acció i tota la trama es concentra en una sola nit de tempesta). Al començament de la novel·la, en plena tertúlia ${ }^{8}$, s'apaguen els llums de cop i ressona un xiscle "de mort" (p. 118), tan esbalaïdor per als qui el senten com el que obre el misteri d'El collar de la Núria, en què, d'altra banda, també es descriu una escena -totalment còmica- relacionada amb l'encesa i l'apagament de llums. Quan la sala es torna a il-luminar, al centre apareix una sabata de dona travessada per un punyal senegalès $i$, atordits per aquest "assassinat" misteriós, els convidats no s'adonen fins més tard-el final del quart capítol- que ha desaparegut una persona: la Rut, l'amant del banquer Joan Encunya, també present a la reunió. Justament durant el sopar la dama lluïa un collar de brillants, "taxat en un milió de pessetes" (p. 150), que el seu company li havia regalat.

\footnotetext{
${ }^{7}$ Cito per la reedició de 1988, i al llarg del text indicaré només la pàgina en què es troba el fragment reproduït.

${ }^{8}$ Tot arrenca amb una narració dins de la narració: a l'inici, l'arqueòleg Camp Gimpoma relata amb suspens una expedició a Egipte a la recerca -precisament-d'un joiell, l'“escarabat de Cleopatra”, al qual s'atribueixen poders sobrenaturals.
} 
Ben aviat es posa en evidència el caràcter interessat d'Encunya, que durant tot el procés de recerca estarà més preocupat per recuperar el joiell que l'amiga, i per això demanarà l'ajuda externa d'un detectiu. En clara referència a El collar de la Núria, el primer investigador que acut al xalet, Goethe (un malalt mental fugat del sanatori), afirma que la desaparició d'un collar "sembla el principi fonamental de tota obra detectivesca que s'estimi” (p. 218). I l'objecte, com recalca Roser Porta (Rodoreda, 2006, p. 151), és esmentat un total d'onze cops al llarg del cinquè capítol. Més endavant, "aterra" al lloc dels fets el detectiu realment contractat, Flac, procedent de Madrid -o sigui, un forà, tal com es presenta Mr. Fog (en realitat, un tarragoní que es fa passar per escocès)-. Tant un com l'altre són reclamats per l'home que havia comprat el collar.

No entraré en detall aquí sobre les correspondències entre alguns personatges d' $E l$ collar de la Núria i de Crim, que ja han estat identificades per Cortés (2001, p. 417418), però val la pena d'anotar, en contrast amb l'enuig del banquer de Crim per la desaparició del joiell, l'incontenible entusiasme de Mr. Xuriguer, que quan no es dedica a les finances es transforma en un "devorador de novel·les policíaques" (p. 206). En una conversa amb Cèsar Franc, afirma: "De tot això que passa, n'estic content! [...] No; no estic content que la Núria passi males estones. Però n'estic molt del misteri, de tots els misteris. Qui és el barbut? Com entra i com surt? Per què fa el que fa? Misteri, misteri i misteri!" (p. 64-65). Resulta especialment significativa, també, la resposta que l'amfitrió dona a Franc quan aquest li fa notar que a la biblioteca hi falten alguns títols elementals del gènere, com els d'Edgar Allan Poe: "Compraré tot el que manqui [...]. Però ara, per sort, tenim millor cosa que llibres. Un misteri de debò i a casa nostra" (p. 67). Una al·lusió força diàfana a la voluntat d'alguns escriptors catalans, i in primis el mateix C. A. Jordana, d'importar el gènere detectivesc i crear una novel·la criminal autòctona.

\subsection{EN PARAL·LEL A LA RECERCA, LA SEDUCCIÓ}

En tots dos casos, doncs, part del misteri sorgeix de la desaparició d'un valuós collar amb què un home adinerat havia obsequiat una dona. El punt de partida és prou similar, i a mesura que la trama avança es posen de manifest encara més aspectes en comú, com la desconcertant successió de les teories de diferents detectius: Goethe i Flac, en el text de Rodoreda; i Mr. Fog, Cèsar Franc i Parnell Samvitx, en el de Jordana. En el segon cas, la sèrie d'hipòtesis és una de les parts més substancioses de la novel-la: no puc repassar-la aquí fil per randa ja que implicaria desviar-me del camí marcat i emprendre'n un ple de revolts.

Un altre punt a remarcar són les relacions sentimentals dels personatges. En la novel·la de Rodoreda, paral·lelament a les investigacions, s'assisteix a l'enamorament de tres parelles: "el ballarí Vessex Boy amb la dama Lady Body, Violeta Balba amb l'historiador Camp Gimpoma i la ballarina Semíramis amb el secretari Xavier 
Corrua" (Cortés, 2001, p. 403). I es podria afegir que els ineficaços interrogatoris de Flac a Lady Body i Semíramis es converteixen, també, en escenes de flirteig. Crim presenta, així, un col·lectiu de personatges que es diverteixen amb el joc de la seducció $i$ amb la possibilitat de canviar les relacions que ja tenen "per unes altres més complexes" (p. 416). Comptat i debatut, si centrem l'anàlisi en els personatges femenins, es constata que són totes "dones de món, vestides i maquillades elegantment; [...] que no tenen cap mena de problema o d'angoixa davant la realitat quotidiana, si deixem de banda un possible canvi d'amant" (Arnau, 1979, p. 51). El misteri de la desaparició de la Rut s'explicarà també per aquest potencial changez l'homme.

Tres quarts del mateix ocorre a El collar de la Núria. Com s'ha apuntat, la Núria té més d'un pretendent: Ramon de Ramonet, per un costat, i, per l'altre, Cèsar Franc -qui, en una escena del capítol tretze que dona lloc a la il·lustració de la coberta, està a punt de declarar-s'hi. Cap dels dos és correspost per la noia. Mentre intenta desar l'amor per la Núria al "caixonet fraternal" (p. 140), Franc té una aventura amb la girl Mary Smiles, i també comença a desitjar una minyona de Vil·la Dick, la Roser. Mr. Xuriguer, al seu torn, mira de seduir aquestes dues mateixes noies, l'artista i l'empleada, per mitjà de collars falsos. I encara es descobreix que dos membres del servei -Antònia, la cuinera; i Mr. Harvey, el majordom-s'han casat secretament per no perdre la feina, atès que, per a l'amo, la solteria dels treballadors és una condició indispensable. Cap de les esmentades fins ara, d'una obra i l'altra, són, però, la parella de personatges clau, que no es donarà a conèixer fins al desenllaç.

\subsection{DESENLLAÇOS DIVERGENTS}

Al final d'El collar de la Núria es destapa que el lladre barbut no ha existit mai. En realitat el xiscle de la noia va ser provocat per un malson. La Núria, en despertar-se i prendre consciència de la situació, tot d'una la va voler aprofitar, mitjançant la invenció d'un atac, per tornar a la seva habitació de sempre. La raó d'aquesta mentida improvisada és que aquella nit havia de rebre d'amagat en Joaquim, el seu amant, d'ofici carboner. La preocupació per la possibilitat que el jove s'escolés a la seva cambra per la finestra i un cop a dins hi trobés el padrastre, Mr. Xuriguer, en lloc de l'estimada, era el que impedia a la Núria de dormir tranquil·la. El collar de perles, d'altra banda, l'havia venut ella mateixa mesos enrere per "produir un capitalet" (p. 253) en previsió del rebuig familiar per la seva relació amb el carboner-de qui espera un fill-, i des de llavors n'ha portat un de fals perquè ningú se n'assabentés ${ }^{9}$. En suma, en cap moment ningú ha intentat robar-lo; xiscles, corredisses, encesa i apagament de llums: tot ha estat part d'una farsa.

\footnotetext{
${ }^{9}$ Malgrat les diferències, l'operació econòmica de la Núria amb el collar pot recordar la de Teresa Goday -protagonista de Mirall trencat, de Mercè Rodoreda- amb l'agulla de pit que li regala el seu primer marit, Nicolau Rovira.
} 
Davant d'aquestes revelacions -en una escena en què només hi són presents la Núria i el tàndem format per Parnell Samvitx i Cèsar Franc-, el cosí de la noia anuncia que ho disposarà tot per obtenir el consentiment familiar i perquè ella i en Joaquim puguin casar-se "El reverend Pringle predicaria a la capella sobre la vanitat de les coses, la igualtat davant Déu i la fraternitat dels homes. Mrs. Xuriguer estaria aleshores a punt de sentir la decisió irrevocable que la Núria havia pres d'esdevenir carbonera" (p. 254). Al capdavall, doncs, El collar de la Núria es mostra com una novel·la d'amor amagada sota l'aparença de novel·la criminal, un camuflatge que també fa servir Mercè Rodoreda en la seva obra, com ha observat Cortés (2001, p. 442).

I és que la idea de renunciar a una còmoda vida burgesa en favor dels sentiments també es fa present a Crim, quan es ve a saber que tot plegat (l'apagament dels llums, el xiscle, la sabata amb el punyal i la desaparició) ha estat orquestrat per l'amfitrió, Marià Frena, i la mateixa Rut amb la complicitat del criat xinès, en Xun-Li. La causa d'aquesta maquinació és que el novel-lista i la dona del banquer són amants i havien planejat fugir junts. En el moment que s'ha extingit la il·luminació, en Marià ha donat la clau del pavelló a la Rut perquè es trobessin allà més tard; ella només havia d'esperar, atès que ja tenia totes les seves pertinences a la casa per partir a l'Aden l'endemà. El pavelló, per cert, també és un dels llocs de trobada de la Núria i en Joaquim, a l'obra de C. A. Jordana.

La descoberta del complot d'una parella d'enamorats dona, però, resultats ben diferents. A Crim, quan la resta de personatges descobreixen la veritat, no ocorre absolutament res. Tots tornen a casa "de la mateixa manera que havien vingut, amb les mateixes parelles" (Cortés, 2001, p. 405), inclosa la Rut:

Joan Encunya es desa el collar a la butxaca. Abans el mira a contrallum. No manca cap pedra. Rut s'agafa del seu braç.

Marià, en un darrer intent, manifesta:

-Això és un crim. Rut no pot anar-se'n. Tot el que he fet ho he fet per ella.

-Hauríeu de conèixer més les dones, amic. [...] Sap prou bé què vol. (p. 290)

És important subratllar que, en la intervenció de Frena, l'elecció del terme "crim" no és gens trivial. El novel lista dona a entendre quin és el vertader delicte comès, als seus ulls: el sobtat canvi d'actitud de la Rut. Al llarg del relat, diversos personatges manifesten què entenen cada un, subjectivament, per crim, amb la mateixa obertura semàntica que farà servir Trabal amb el verb present en el títol de la novel·la $L$ 'home que es va perdre (1929); d'aquesta manera Rodoreda juga amb el concepte que intitula els esdeveniments i li'n resta gravetat: "Penseu que la vida és curta i malbaratar-ne els minuts és un crim" (p. 201). "El gran crim de la vida és l'avorriment, la comprensió i la sexualitat... Tot això assassina l'amor!" (p. 232). "La meva íntima tragèdia és que no sóc lliure. Tinc un amant. Gelós... [...] Aquest és el meu crim. La meva dissort. [...] Quin desconhort!" (p. 258), "Quin gran bé que ha fet en mi aquesta nit. No és un crim que ens enderiem a defugir allò que ens pot ben guarir?" (p. 271). 
Si bé Joan Encunya, per la seva banda, qualifica de crim l'estat d'empastifament en què retroba el collar de brillants, amagat en un pot de cuina, al començament de la nit havia tret importància al crim "elegant, simpàtic" (p. 138) de la sabata apunyalada. "Per què capficar-nos en una banalitat que no farà augmentar els valors?" (p. 132), planteja el banquer a la resta de personatges. Tornant a les darreres pàgines de la novel·la, sembla que la Rut hagi fet la mateixa reflexió sobre el benefici econòmic de la seva decisió $i$ hagi comprès que els versos d'amor de Marià Frena, per eloqüents que siguin, no tindran mai el poder de fer que els valors pugin. Així, reordena les seves prioritats i decideix fer-se enrere en l'aventura planejada:

-Adéu Marià. Podràs esquinçar la meva lletra... és tan ridícula... no tant com la teva, però. Quant al viatge és deliciós de fer-lo sol...

I Rut riu.

Ella i el banquer abandonen el saló. (p. 291)

Amb aquest final tan teatral es clou la paròdia. La Rut se'n va amb el mateix amant amb qui havia arribat, no canvia els brillants per les lletres i es restableix la situació original.

\section{CONSIDERACIONS FINALS}

Recollint el que s'ha desgranat, es fa evident que la història de Mercè Rodoreda es configura a partir de la imitació, grosso modo, de la trama d'El collar de la Núria i, sobretot, de la inversió del seu desenllaç - com és, de fet, propi de la forma paròdica (Hutcheon, 1985, p. 6)-, que l'autora reescriu "a la seva manera". Tal adaptació, en aquest cas, s'esdevé en la ridiculització del sentimentalisme d'en Marià i de la Rut (les "Pastanaguetes enamoradetes" que s'envien cartes) i en la negació del triomf d'aquesta unió, de forma contrària al final feliç que C. A. Jordana brinda als personatges de la Núria i en Joaquim.

També en la dimensió simbòlica es constata que el motor narratiu que representa la pèrdua del collar -i torno ara a Chevalier i Gheerbrant (1986)- es pot relacionar directament amb l'alteració de l'ordre social que impera al principi del relat. Això es deu al fet que, en les dues obres, aquest ordre és "desafiat" per una relació amorosa extraoficial; tanmateix, només en una, El collar de la Núria, la relació prospera i l'statu quo acaba per alterar-se. Qui resol el dilema de decidir entre dos mons oposats és la portadora del joiell: mentre que la Núria està disposada a perdre les perles i la seva situació socioeconòmica per casar-se amb el carboner, la Rut no es deixa convèncer per les inspirades paraules del novel-lista, i resol quedar-se el collar i continuar essent l'amant d'un banquer, per bé que es tracti d'un home avar i materialista. 
Amb aquesta lectura comparada, l'obra de Rodoreda revela una faceta nova: no només és la paròdia dels principis d'un gènere -com ja se sabia-, sinó que també ho és d'una paròdia anterior d'aquest mateix gènere, en un exercici de reescriptura que segella el vincle entre els dos títols i que dona lloc al que podríem anomenar, seguint la terminologia de Genette, la hiperparòdia (o paròdia al quadrat). En aquest sentit, la narració del 1936 també encaixa perfectament en la definició de paròdia de Michelle Hannoosh (1989, p. 114) citada més amunt: és una nova versió d'una història anterior.

Així, doncs, Mercè Rodoreda recupera l'obra poc coneguda de C. A. Jordana, amb què el seu text de preguerra passa a formar un díptic paròdic les dues parts del qual es poden llegir com a complementàries. Des d'aquest punt de vista, resulta una coincidència afortunada que Rafael Tasis i Manuel de Pedrolo mencionessin respectivament El collar de la Núria i Crim en ser interrogats sobre els orígens de la narrativa policíaca a Catalunya. De forma no premeditada, tots dos grans autors del gènere foren dels primers en posar-les una al costat de l'altra, amb tot l'encert.

\section{AGRAÏMENTS}

Aquest estudi ha estat possible gràcies a un ajut per a la Formació de Professorat Universitari (FPU) del Ministeri de Ciència, Innovació i Universitats (referència FPU17/04873). 


\section{REFERÈNCIES BIBLIOGRÀFIQUES}

Arnau, C. (1979). Introducció a la narrativa de Mercè Rodoreda. El mite de la infantesa. Barcelona: Edicions 62.

Campillo, M. (2006). Mercè Rodoreda: París 1939 (quatre cartes i unes botes). Els Marges: Revista de llengua i literatura, 78, 107-112. Recuperat de https:/www.raco.cat/index.php/Marges/article/ view/142420.

Campillo, M. (ed.) (1993). C. A. Jordana: 1893-1993. Centenari. Barcelona: Departament de Cultura de la Generalitat de Catalunya \& Institució de les Lletres Catalanes.

Chevalier, J. \& Gheerbrant, A. (1986). Diccionario de los símbolos (trad. de M. Silvar \& A. Rodríguez). Barcelona: Herder.

Cortés, C. (2001). Les primeres novel-les de Mercè Rodoreda (1932-1936). Repositori Institucional de la Universitat d'Alacant. Recuperat de https://rua.ua.es/dspace/handle/10045/10024 [Tesi doctoral dirigida per E. Balaguer].

Genette, G. (1982). Palimpsestes: la littérature au second degré. París: Seuil.

Gregori, C. (2016). Gènere negre i ironia en els inicis literaris de Mercè Rodoreda. Dins F. Carbó, C. Gregori \& R. X. Rosselló (eds.), La ironia en les literatures occidentals des de l'inici de segle fins a 1939 (p. 476-496). Barcelona: Publicacions de l'Abadia de Montserrat.

Hannoosh, M. (1989). The Reflexive Function of Parody. Comparative Literature, 41 (2), 113-127. DOI: $10.2307 / 1770971$

Hutcheon, L. (1985). A Theory of Parody: The Teachings of Twentieth-Century Art Forms. Londres: Methuen.

Jordana, C. A (1988). El collar de la Núria. Barcelona: Curial Edicions Catalanes [Publicat originalment el 1927].

Manent, A. (1961). Enquesta: La novel-la policíaca a Catalunya. Serra d'Or, 7, 13-14.

Martínez-Gil, V. (ed.) (2004). Els altres mons de la literatura catalana. Antologia de narrativa fantàstica i especulativa. Barcelona: Galàxia Gutenberg \& Cercle de Lectors.

Muñoz, T. (1992). Entrevistes de Mercè Rodoreda a "Clarisme" (1933-1934). Estudis de Llengua i Literatura Catalana, 5, 495-573. Recuperat de https://www.raco.cat/index.php/LlenguaLiteratura/article/ view/220404.

Porta, R. (2007). Mercè Rodoreda i l'humor (1931-1936): primeres novel·les, el periodisme $i$ Polèmica. Barcelona: Fundació Mercè Rodoreda \& Institut d'Estudis Catalans.

Rodoreda, M. (2002). Primeres novel·les, II (ed. de R. Porta). Barcelona: Fundació Mercè Rodoreda \& Institut d'Estudis Catalans.

Roig, M. (1976). Retrats paral·lels, II. Barcelona: Publicacions de l'Abadia de Montserrat.

Saladrigas, R. (1979). Literatura i societat a la Catalunya d'avui. Barcelona: Publicacions de l'Abadia de Montserrat.

Vázquez de Parga, S. (1993). La novela policiaca en España. Barcelona: Ronsel. 